\title{
LABORATORY SIMULATION OF COMETARY STRUCTURES
}

\author{
KH.I. IBADINOV, A.A. RAHMONOV, A.SH. BJASSO \\ Institute of Astrophysics of the Tadjik Academy of Science, \\ 734670, Dushanbe, USSR
}

\begin{abstract}
The properties of a porous mineral crust on the surface of an icy cometary nucleus and the crust's influence on the thermal regime and gas production in the nucleus have been studied by laboratory simulation experiments. A nucleus model of $\mathrm{H}_{2} \mathrm{O}$ ice with the impurity of graphite particles has been shown to display the same temperature and surface albedo as those determined for Comet Halley's nucleus by the VEGA 1, VEGA 2, and Giotto spacecraft. The effective thermal conductivity of a crust with a density of $0.5 \times 10^{2} \mathrm{~kg} \mathrm{~m}^{-3}$ to $0.7 \times 10^{2} \mathrm{~kg} \mathrm{~m}^{-3}$ is less than $10^{-1} \mathrm{~W} \mathrm{~m}^{-1} \mathrm{~K}^{-1}$, while the crust's strength $\left(10^{3}\right.$ to $\left.10^{4} \mathrm{~Pa}\right)$ is not sufficient to withstand its erosion by the sublimating gases. A crust that is $1 \mathrm{~cm}$ thick lowers the gas production of the nucleus model by one order of magnitude. The destruction of the crust, and the gas and dust production of Comet Halley's nucleus can be explained either by a spotty surface on the nucleus or, more likely, by the presence of volatile impurities such as $\mathrm{CO}_{2}$ with concentrations of $1 \times 10^{-2}$ to $3 \times 10^{-2}$ in the $\mathrm{H}_{2} \mathrm{O}$ ice under the crust.
\end{abstract}

\section{Introduction}

Laboratory investigations based on Whipple's $(1950,1951)$ comet nucleus model have shown that, in the course of the sublimation, a surface of either pure ice or ice with impurities becomes complex. Thus, under experimental conditions equivalent to the conditions at heliocentric distances of $\mathrm{R}<1 \mathrm{AU}$, filamentary structures are formed in the process of sublimation, due to molecular recrystallization (Ibadinov 1989). Impurities in the ice composition can influence the ice's sublimation. The sublimation of a water- $\mathrm{CO}_{2}$ mixture, for example, can be accompanied by microbursts of gas at the surface, even if the concentration of $\mathrm{CO}_{2}$ in the ice composition is small (Ibadinov and Aliev 1984, 1987). This is because $\mathrm{CO}_{2}$ ice sublimates at lower temperatures than $\mathrm{H}_{2} \mathrm{O}$ ice. In this case, the icy dust particles are ejected from the surface under cometary conditions. If the admixture in the ice sublimates at higher temperatures than the water ice does, a crust made up of this impurity can be formed under certain conditions (Dobrovolsky and Kajmakov 1977; Grün et al. 1987; Ibadinov 1989; Ibadinov and Aliev 1984, 1987; Ibadinov and Kajmakov 1970; Kajmakov and Ibadinov 1971; Lizunkova et al. 1977; Matveev and Kajmakov 1980; Shul'man 1972, 1987; Whipple 1950, 1951). The thermal regime, the sublimation rate, 
and the conditions of dust ejection from the surface of such a nucleus model are determined as a whole by the properties of this crust and by the gas pressure under it.

There is both indirect evidence (the dependence of the secular brightness decrease of short-period comets on their perihelion distance (Dobrovolsky et al. 1984, 1986) and direct evidence (the study of characteristic features on Comet Halley's nucleus by the VEGA 1, VEGA 2, and Giotto spacecraft (Reinhard 1986, Sagdeev et al. 1986) of the presence of a crust on the surfaces of the nuclei of a great number of short-period comets. The surfaces of the nuclei of some long-period and new comets also appear to be covered by a mineral crust.

Theoretical investigations show that the crust has an important role to play in the evolution of comets and the gas production from a number of comets, including Comet Halley (Dobrovolsky and Ibadinov 1971; Markovich 1958, 1961, 1986; Mendis and Brin 1977; Riives 1966; Shul'man 1972, 1987; Whipple 1950, 1951). However, it is difficult to explain these phenomena with a model of an icy nucleus that is covered everywhere by a mineral crust. This discrepancy alone requires that the original version of Whipple's model of a cometary icy nucleus be modernized. The gas production from real comets can be explained within the framework of the above model, if the nucleus is not covered everywhere by a mineral crust (the spotty model of a nucleus (Shul'man 1972, 1987)) or if the crust is destroyed quasi-continuously (Grün et al. 1987, Ibadinov and Kajmakov 1970, Kajmakov and Ibadinov 1971). In both cases, the influence of properties of the crust and of its formation and destruction is substantial. Thus, the study of structures such as mineral crusts on the surfaces of cometary nuclei proved to be timely, especially since the space missions to Comet Halley.

We have studied, by laboratory simulation, the sublimation of different types of cometary icy materials (a review of some of the results is given in Ibadinov (1989)). We obtained experimental data concerning the conditions under which the mineral crust on the surface of the subliming ices is being formed and destroyed. The present paper is devoted to the results of laboratory investigations of the process of the mineral crust's formation on the surface of cometary nuclei, and the properties of this crust. We will also discuss the contribution of the mineral crust to the thermal regime and the gas production from an icy cometary nucleus.

\section{Methods and Techniques of the Laboratory Comet Simulation Experiments}

It is hardly possible to create in the laboratory the conditions under which the nuclei of real comets exist. One can only approximate the conditions of real comets, in a way dependent on the problem to be solved. Following the goal of this paper, it is necessary to simulate, under laboratory conditions, the sublimation of composite cometary ices under irradiation imitating solar irradiation. It can be shown that, under conditions that exist inside $3 \mathrm{AU}$, nucleus sublimation occurs mainly from the visible part of solar irradiation. Numerous experiments show that sublimation of cometary ices can be successfully simulated in a high vacuum in which the free-molecular flow of gases is guaranteed and in which the sublimation products are effectively removed by means of liquid nitrogen cryostats (Dobrovolsky and Kajmakov 1977; Dobrovolsky et al. 1984, 1986; Grün et al. 1987; Ibadinov 1989; Ibadinov and Kajmakov 1970; Kajmakov and Ibadinov 1971; 
Klinger et al. 1989; Kochan et al. 1989; Lizunkova et al. 1977; Matveev and Kajmakov 1980). Solar irradiation can be simulated with high-pressure lamps containing xenon, mercury-xenon, and mercury gas.

In our experiments, we have used two devices for the laboratory cometary simulation. The vacuum chamber described in Ibadinov (1989) has been modernized and made more universal (Figure 1(a)). Because of these changes, not only could the rate of sublimation and crust formation be studied, but experiments determining the reflectivity of comet model surfaces and the structural properties of the mineral crust could also be carried out. The vacuum chamber in which the experiments on the thermal conductivity of nucleus models were conducted was described in Ibadinov et al. (1987b).

The samples of cometary nucleus model materials were prepared using liquid nitrogen vapor to freeze mixtures of distilled water and different impurities. Although sample containers of different designs and materials were used, most experiments were carried out with samples made in a thin-walled cylindrical container (Figure 1(b)) consisting of low-thermal-conductivity materials such as cork and Styrofoam. Dust particles of graphite, quartz, and nickel between 1 and $30 \mu \mathrm{m}$ in size, as well as organic substances such as DL- alanine, DL- threonine, and L- valine, were added as impurities to the $\mathrm{H}_{2} \mathrm{O}$ ice. After a sample was frozen in liquid nitrogen vapors, it was placed into the chamber. The chamber was pumped down to a pressure of $10^{-4} \mathrm{~Pa}$, and at the same time, the sample was cooled by a cryostat with the liquid nitrogen. The temperature of this cryostat surrounding the nucleus model was $80 \mathrm{~K}$. The irradiation of a sample with a beam of light took place after a low temperature for the sample and a high vacuum in the chamber had been achieved.

The experiments have shown that the mineral surface crust of most ice nucleus models is quasi-continuously destroyed by the stream of sublimed molecules, if the crust is irradiated by a light beam intensity that is equivalent to the intensity of solar irradiation at heliocentric distances $\mathrm{R} \approx 0.5 \mathrm{AU}$. If the light beam's intensity on the surface of the nucleus model is low (for example, when the energy is equivalent to that at $R \approx 3 \mathrm{AU}$ ), the time required for crust formation quickly increases. The intensity range $E$ equivalent to the solar irradiation intensity at 1 to $2 \mathrm{AU}$ proved to be the most optimal in obtaining a crust $1 \mathrm{~cm}$ thick. It took up to 200 hours of continuous irradiation of model surfaces to produce a crust 0.5 to $1 \mathrm{~cm}$ thick, even under the above conditions. The experiment itself sometimes lasted for about 10 days.

The temperature $\mathrm{T}$, the sublimation rate $\mathrm{I}$ of the nucleus models, the coefficient of diffuse reflection $A$ of light from their surfaces, the parameters characterizing the density $\rho_{c}$, the strength $P_{c}$, and the thermal conductivity $\lambda$ of the crust have been measured in the experiments. As in every experiment, the measuring devices and the experimental methods are subject to errors. When measuring $E, I$, and $\rho_{c}$, the errors can reach $10 \%$ of the value, while the errors made when measuring $A, P_{c}$, and $\lambda$ can amount to $20 \%$. The errors made in measuring temperatures do not exceed $2^{\circ}$.

\section{Experimental Results}

It is known that when the incident light energy is constant and the temperature is balanced, the rate of pure ice's sublimation is constant in time, and the thickness of the sublimed ice layer is proportional to time $t$. When the ice contains refractory impurities that 


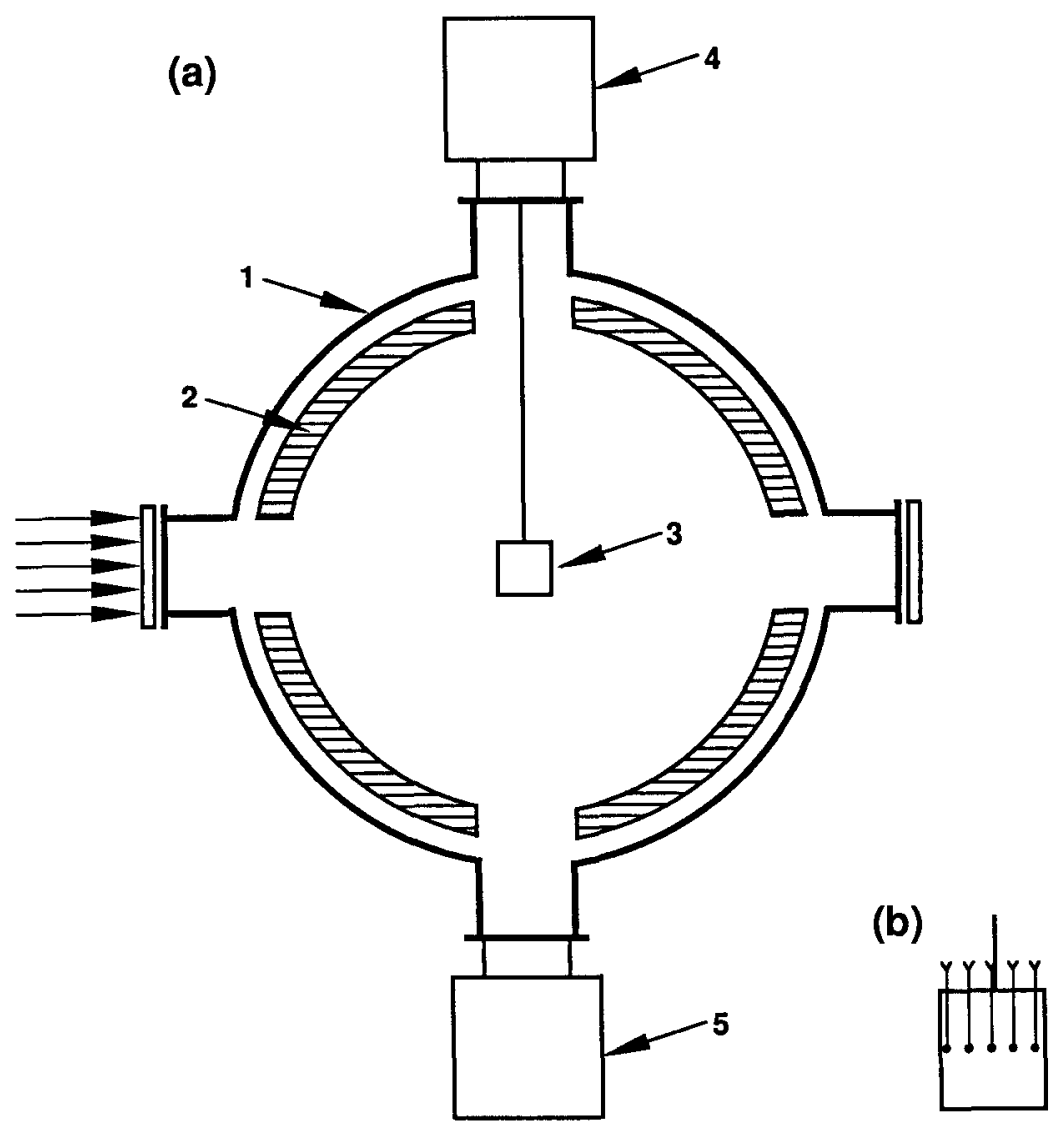

Figure 1. (a) A schematic drawing of the high-vacuum chamber (viewed from above) for the investigation of cometary nucleus models' sublimation, measurements of surface reflectivity, and measurements of the mineral crust's strength. $1=$ the wall of the steel chamber, $2=$ the cryostat with liquid nitrogen, $3=$ the container with the sample, $4=$ the mechanism for removal and rotation of the sample, and $5=$ the electrooptic camera. (b) The schematics of the sample container with thermocouples.

can form a porous crust on the surface of the ice, the rate of ice sublimation is not constant in time, but rather it decreases with time $t$, since the crust becomes thicker with time. There are different ways of determining the crust thickness on the surface of sublimed ice in the laboratory experiments. It can be determined, for instance, from the experimental function $\mathrm{I}(\mathrm{t})$, if the permeability of the crust has been determined independently, or from the 
(a)

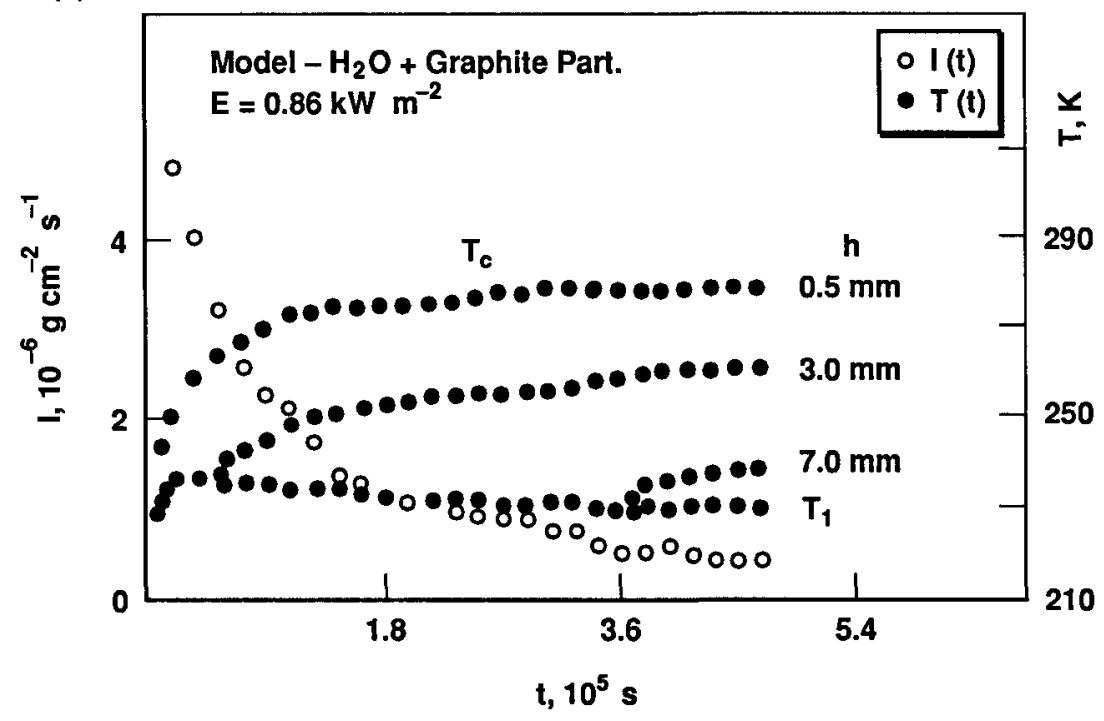

(b)

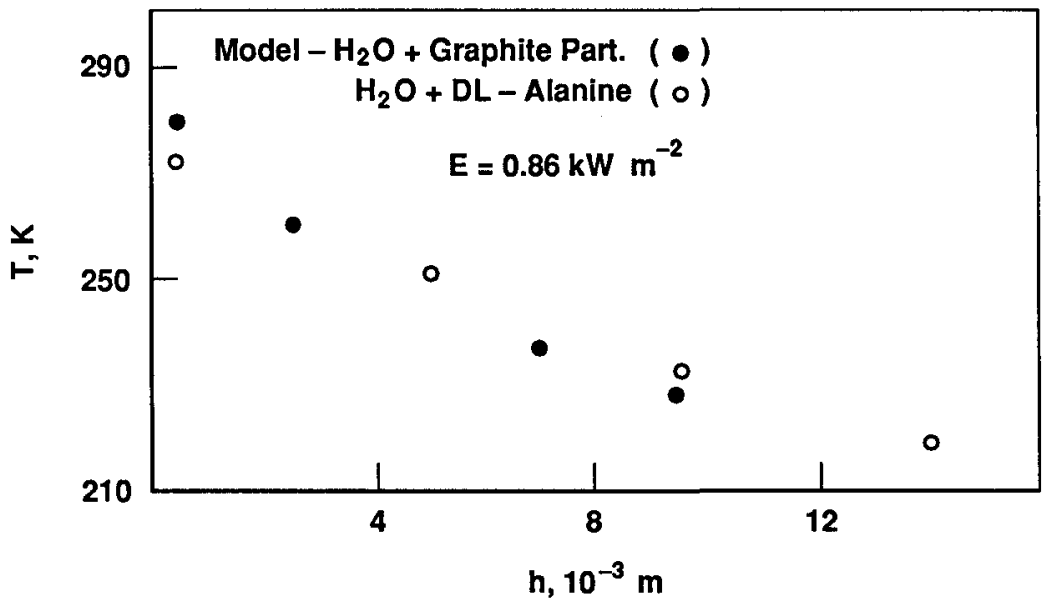

Figure 2. (a) The time dependence of the sublimation rate $I(t)$ and temperature of a sample with a mineral crust. (b) The temperature $T(t)$ distribution as a function of the crustal depth after about 60 hours of irradiation.

thermocouple recordings made at a particular depth $\mathrm{h}$ of a sample. Figure 2(a) shows a typical graph of dependence $I(t)$ and $T(t)$ in cometary models under constant irradiation. To avoid having direct light hit the first thermocouple, that instrument was placed at a depth of $\mathrm{h}_{1}=0.5 \mathrm{~mm}$ from the surface. 
Before a sample was irradiated, its temperature was approximately the same throughout. After irradiation, the sample was warmed up, and the steady-state temperature profile corresponding to the value of the light intensity $\mathrm{E}$ was gradually established. Once the crust formed, the surface temperature increased, and the temperature distribution with depth $\mathrm{h}$ became linear (Figure 2(b)). As the crust thickened, the ice-crust boundary moved down into the sample. When the boundary reached the thermocouple at the depth $h_{1}$ and this thermocouple was released from the ice, a new crust temperature at this depth was established. As the crust became thicker and succeeding thermocouples were released at the depths $h_{2}, h_{3}, \ldots$, this process was repeated (Figure 2(a)). Thus the thickness of the crust was determined by measuring the sudden changes in the readings of the thermocouples at depths $h_{1}, h_{2}, h_{3}, \ldots$ at times $t_{1}, t_{2}, t_{3}, \ldots$. According to the experimental dependence of $I(t)$, it is evident that if the impurity in the ice volume is uniformly distributed, $\mathrm{H}=\mathrm{I} / \rho$, where $\rho=\mathrm{M}_{\mathrm{H}_{2} \mathrm{O}} / \mathrm{V}_{0}, \mathrm{M}_{\mathrm{H}_{2} \mathrm{O}}$ is the mass of the ice in the sample, and $\mathrm{V}_{\mathrm{o}}$ is the sample volume.

The measurements of the crust thickness $\mathrm{H}$ by these methods are in good agreement with each other. The typical experimental dependence of $\mathrm{H}(\mathrm{t})$ and $\mathrm{I}(\mathrm{H})$ are shown in Figure 3. It can be seen that $\mathrm{H}(\mathrm{t})$ is a power function of time; $\mathrm{H}=\mathrm{C} \mathrm{t} \mathrm{k}$. The constants $\mathrm{C}$ and $\mathrm{k}$ can easily be deduced from the statistical analysis of the experimental results. Within the experimental errors, the constant $k=1 / 2$ (Table 1 ). Then

$$
\mathrm{H}=\mathrm{C} \mathrm{t}^{1 / 2}
$$

and

$$
I=\frac{C^{2}}{2} \rho / H=D \rho / H
$$
It follows from (1) that $\frac{\mathrm{C}^{2}}{2}=\mathrm{H}^{2} /(2 \cdot \mathrm{t})=\mathrm{D}$ is a diffusion coefficient and $\mathrm{t}$ is the formation
time of the mineral crust.

The transfer of heat into the cometary nucleus and laboratory nucleus models is known to take place by thermal conductivity across the contacts of crust particles, by means of thermal radiation and gas conduction. The estimation of each heat transfer channel was not the aim of our experiments, but we determined the total effective heat conductivity $\lambda_{\text {eff }}=\mathrm{E}(1-\mathrm{A}) \Delta \mathrm{h} / \Delta \mathrm{T}$ of the crust (Ibadinov et al. 1987b). To this end, we measured the temperature distribution throughout the crust for each value of $\mathrm{E}$. The coefficient of diffuse reflection from this surface was determined when the angle of incidence on the surface of the samples was $45^{\circ}$. Milk glass was used as a standard. It can be seen from Table 1 that for most nucleus models whose crust is composed of organic substances, A lies in the range of 0.5 to 0.6 and is close to the $A$ for rough water ice. For the nucleus model with graphite particles making up the mineral crust, $A=0.06$ at the beginning of the experiment, when the crust is just beginning to form, and $A=0.04$ at the end of the experiment, when the crust is quite thick.

Table 1 gives the types of nucleus models, as well as data on the experimental conditions, crust properties, the crust temperature $T_{c}$ at the depth $h=0.5 \mathrm{~mm}$, the ice temperature under the crust $\mathrm{T}_{\mathrm{i}}$, and constants $\mathrm{k}$ and $\mathrm{D}$, characterizing crust growth. The mechanical strength of the crust $\mathrm{P}_{\mathrm{c}}$ was determined by the crushing method with a ball stamp (Ibadinov 1982; Ibadinov et al. 1985, 1987a). This method was applied under conditions of high vacuum when the ice sublimation continued underneath the crust and the 
(a)

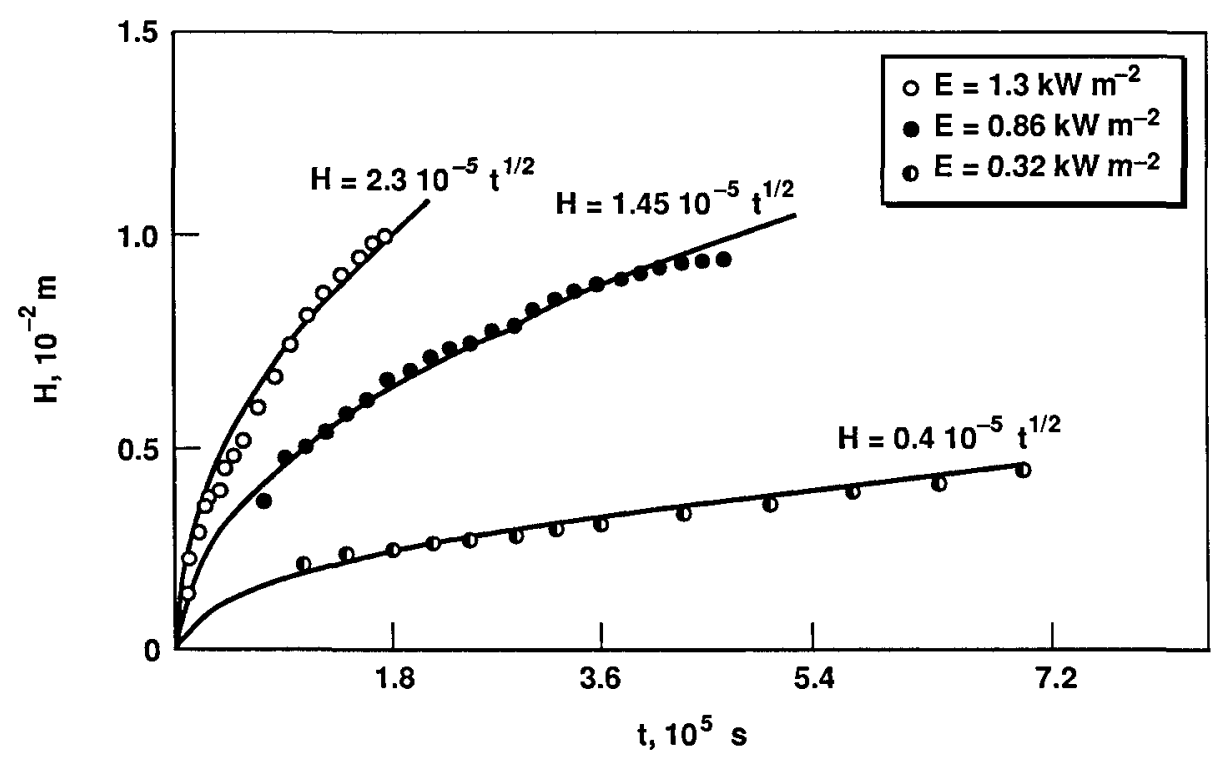

(b)

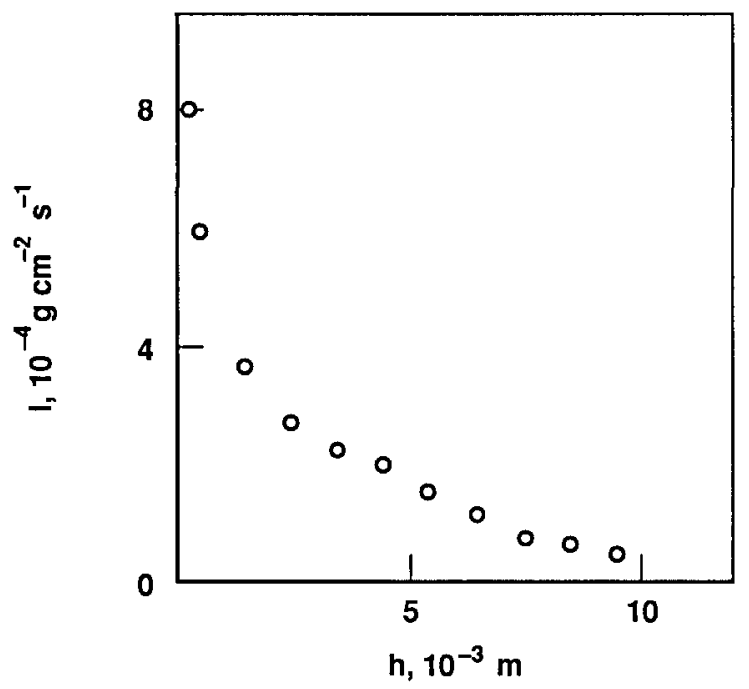

Figure 3. (a) The dependence of the crust thickness on the sublimation time of the nucleus models. (b) The dependence of the sublimation rate on the crust thickness. 
Table 1. The Properties of Crust Models of Icy Comet Nucleus Surfaces

\begin{tabular}{|c|c|c|c|c|c|c|c|c|c|c|}
\hline $\begin{array}{l}\text { Models of } \\
\text { the Nucleus }\end{array}$ & $\begin{array}{l}\mathrm{E}, \\
\frac{\mathrm{kW}}{\mathrm{m}^{2}}\end{array}$ & $\begin{array}{l}\mathrm{R}, \\
\mathrm{AU}\end{array}$ & $\begin{array}{c}\text { Porous, } \\
\%\end{array}$ & $\begin{array}{l}\rho_{c} \\
\frac{\mathrm{kg}}{\mathrm{m}^{3}} \\
\end{array}$ & $\begin{array}{c}\mathrm{T}_{\mathrm{c}} \text { at } \\
\mathrm{h}= \\
0.5 \mathrm{~mm} \\
\mathrm{~K}\end{array}$ & $\begin{array}{c}\mathrm{T}_{\mathrm{i}} \\
\mathrm{K}\end{array}$ & $\begin{array}{l}P_{c}, \\
\mathrm{kPa}\end{array}$ & $\begin{array}{l}\lambda_{\text {eff, }}, \\
\frac{\mathrm{W}}{\mathrm{mK}}\end{array}$ & k & $\begin{array}{c}\mathrm{D} \\
10^{-10} \\
\frac{\mathrm{m}^{2}}{\mathrm{~s}} \\
\end{array}$ \\
\hline \multicolumn{11}{|l|}{$\begin{array}{c}\mathrm{H}_{2} \mathrm{O} \text { ice } \\
\text { with im- } \\
\text { purities } \\
\text { from: }\end{array}$} \\
\hline \multirow{3}{*}{$\begin{array}{l}\text { Graphite } \\
\text { particles }\end{array}$} & 0.32 & 2 & 80 & 470 & 230 & 193 & 20 & 0.05 & 0.43 & 0.16 \\
\hline & 0.86 & 1.3 & 80 & 470 & 278 & 224 & 14 & 0.07 & 0.57 & 2.0 \\
\hline & 1.3 & 1 & 80 & 470 & 325 & 232 & 15 & 0.08 & 0.53 & 5.3 \\
\hline $\begin{array}{c}\text { Quartz } \\
\text { particles }\end{array}$ & 1.35 & 1 & 40 & 1,360 & - & - & 39 & 0.08 & - & - \\
\hline $\begin{array}{c}\text { Nickel } \\
\text { particles }\end{array}$ & 1.35 & 1 & 60 & 3,100 & - & - & - & 0.1 & - & - \\
\hline DL-alanine & 0.92 & 1.2 & 97 & 22 & 271 & 219 & 2 & 0.05 & 0.51 & 1.7 \\
\hline $\begin{array}{c}\text { DL- } \\
\text { threonine }\end{array}$ & 0.86 & 1.3 & 96 & 31 & 250 & 220 & 5 & 0.05 & 0.52 & 1.7 \\
\hline L- valine & 0.86 & 1.3 & 96 & 30 & 250 & 215 & 2 & 0.04 & 0.50 & 1 \\
\hline \multicolumn{9}{|l|}{ 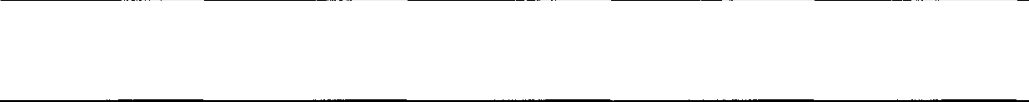 } & \pm 0.0 & \\
\hline
\end{tabular}

sublimation products passed through it. It can be seen that the effective thermal conductivity of the mineral crust does not exceed $10^{-1} \mathrm{~W} \mathrm{~m}^{-1} \mathrm{~K}^{-1}$, while the crust's strength is within the range of $10^{3}$ to $10^{4} \mathrm{~Pa}$. The very small diffusion coefficient gives evidence that the gas mobility through the crust is small and that the gas pressure under the crust is close to the saturation vapor pressure of ice. The ice temperature under the crust is within the range of 193 to $232 \mathrm{~K}$, and the vapor pressure of $\mathrm{H}_{2} \mathrm{O}$ ice is not large enough to destroy the crust, the strength of which is given in Table 1.

\section{Possible Composition and Structure of the Surface of Comet Halley's Nucleus}

According to the VEGA 1, VEGA 2, and Giotto data, the surface of Comet Halley's nucleus has a temperature of 320 to $400 \mathrm{~K}$ (Emerich et al. 1986) or $420 \pm 60 \mathrm{~K}$ (Combes et al. 1986), and a low albedo (in the 0.03 to 0.06 range). Approximately $80 \%$ of the molecules of the cometary atmosphere is $\mathrm{H}_{2} \mathrm{O}$ (Reinhard 1986, Sagdeev et al. 1986). It follows from our experiments that the most similar type of the laboratory nucleus models might be the nucleus model containing a mixture of $\mathrm{H}_{2} \mathrm{O}$ and graphite particles. Under the experimental conditions that are equivalent to the conditions at $\mathrm{R} \approx 0.8 \mathrm{AU}$ (Comet Halley's heliocentric distance at the time of the spacecraft passages through the comet's 
head), the temperature of the subsolar surface point of our model is equal to $360 \pm 10 \mathrm{~K}$ (Ibadinov and Rahmonov 1988).

Let us numerically calculate the temperature, the sublimation rate, and the crust thickness for a cometary nucleus made up of a mixture of $\mathrm{H}_{2} \mathrm{O}$ ice and graphite particles under the conditions of the laboratory experiment. To this end, let us assume that the comet's orbit is circular and that the period of the nucleus rotation about its axis is $\tau=\infty$. Let us also consider the subsolar point of the nucleus surface in detail. In accordance with the experimental results, let us take the minimum size of the particles in the ice composition to be $\mathrm{d}_{\min }=10^{-3} \mathrm{~cm}$, the surface albedo $\mathrm{A}=0.05$, the crust porosity $=80 \%$, the thermal conductivity of the crust $\lambda=0.05 \mathrm{~W} \mathrm{~m}^{-1} \mathrm{~K}^{-1}$, and the original thickness of the crust $\mathrm{H}_{0}=10^{-2} \mathrm{~cm}$. The results obtained from our calculation, based on the mathematical model of Fanale and Salvail (1984), for the crust temperature $T_{c}$, the ice temperature $T_{i}$ under the crust, the crust thickness $H$, and the sublimation rate I (Figure 4(a)) are in good agreement with the results obtained from the laboratory experiments (Figure 2 and Table 1).

To calculate the thermal regime and the gas production of Comet Halley's nucleus, let us assume that the nucleus composition is the same as in the simulation experiments and that there is a crust of $\mathrm{H}_{0}=10^{-2} \mathrm{~cm}$ thickness at the distance of $4 \mathrm{AU}$ from the Sun. We further assume that the energy that reaches the ice-crust boundary is spent for the sublimation of $\mathrm{H}_{2} \mathrm{O}$ ice. The calculations of $\mathrm{T}_{i}, \mathrm{~T}_{\mathrm{c}}, \mathrm{I}$, and $\mathrm{H}$ for the subsolar point of the nuclear surface are presented in Figure 4(b). The orbital elements were taken from Yeomans (1986), and the nuclear rotation period about its own axis was assumed to be $\tau=53 \mathrm{~h}$ (Sekanina and Larson 1986).

It can be seen that the crust temperature increases rapidly as the comet comes nearer to perihelion, where the subsolar point of the nuclear surface is warmed up to $470 \mathrm{~K}$. The mineral crust reaches a thickness of several centimeters, while the temperature at the icecrust boundary is hardly increased and does not exceed $T_{i}=230 \mathrm{~K}$. The gas production post-perihelion is less than it is pre-perihelion, and it is strongly asymmetrical in relation to perihelion. The difference in the cometary brightness before and after perihelion at a distance of $\mathrm{R}=1 \mathrm{AU}$ amounts to $\sim 0^{\mathrm{m}} .6$, and this difference increases as $\mathrm{R}$ grows, reaching $\sim 4^{\mathrm{m}}$ at $\mathrm{R} \approx 3.8 \mathrm{AU}$.

The results of the laboratory and numerical simulations of the cometary nucleus covered with a mineral crust show that, at the first orbit around the Sun, the comet quickly loses its brightness, and the nucleus is covered everywhere with a thick crust. This cannot be accepted in the case of Comet Halley.

Analyses of Comet Halley's atmospheric molecular composition show that there are other gases present besides $\mathrm{H}_{2} \mathrm{O}$ molecules, e.g., $1 \%$ to $3 \% \mathrm{CO}_{2}$ has been found in the comet's head (Reinhard 1986, Sagdeev et al. 1986). If one assumes that the $\mathrm{CO}_{2}$ molecules are the sublimation products of $\mathrm{CO}_{2}$ ice, a $1 \%$ to $3 \% \mathrm{CO}_{2}$ impurity has to be contained in the $\mathrm{H}_{2} \mathrm{O}$ ice. To obtain a qualitative picture and some quantitative estimates without considering in detail the complicated chemical composition of the nucleus, let us consider the sublimation of the $\mathrm{H}_{2} \mathrm{O}$ ice with impurities of $\mathrm{CO}_{2}$ and graphite particles, and compare the results with those obtained from laboratory investigations of ice sublimation with $\mathrm{CO}_{2}$ as an impurity (Ibadinov 1989; Ibadinov and Aliev 1984, 1987).

Experimental studies have demonstrated that the sublimation of $\mathrm{H}_{2} \mathrm{O}$ ice that contains even negligible amounts of $\mathrm{CO}_{2}$ impurities is accompanied by microbursts at the ice surface and by the ejection of ice particles (Ibadinov 1989, Ibadinov and Aliev 1987). 
(a)
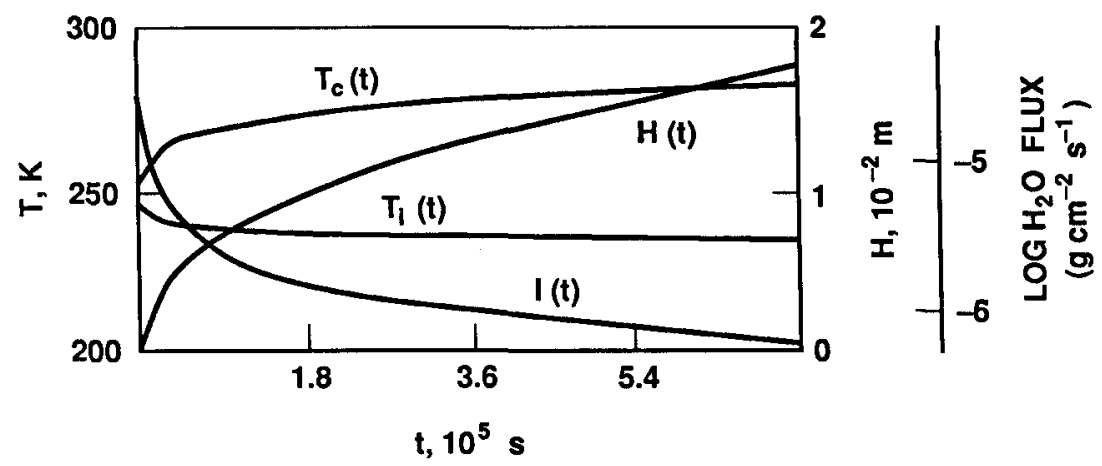

(b)
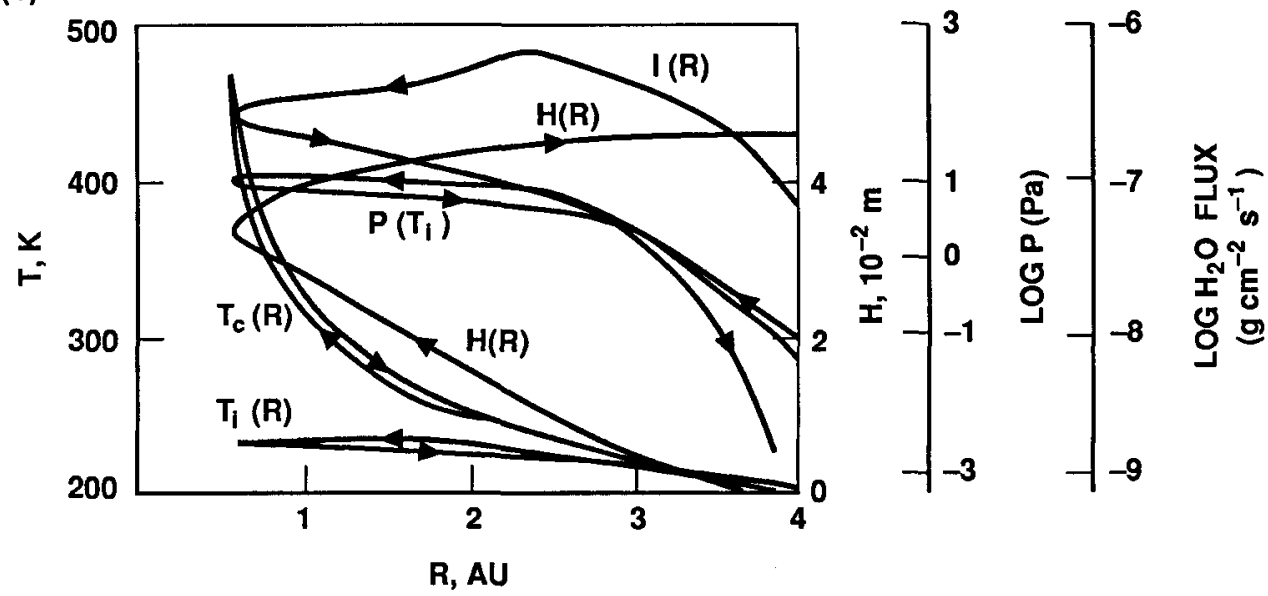

Figure 4. Results of the numerical simulation of the thermal regime, gas production rate, and crust thickness of the subsolar point of a cometary nucleus surface. In this nucleus model, $\mathrm{H}_{2} \mathrm{O}$ ice contains graphite particles whose minimum size $d_{\min }=10^{-3} \mathrm{~cm}$. The parameters of the crust are as follows: $\mathrm{H}_{\mathrm{o}}=10^{-2} \mathrm{~cm}, \mathrm{~A}=0.05$, porosity $=80 \%$, $\lambda=0.05 \mathrm{~W} \mathrm{~m}^{-1} \mathrm{~K}^{-1}$. (a) For conditions equivalent to those of the experimental simulations at $\mathrm{E}=0.86 \mathrm{~kW} \mathrm{~m}^{-2}(\mathrm{R}=1.25 \mathrm{AU})$.

(b) For Comet Halley's nucleus. 
It takes 552 cal of energy to support the sublimation of $1 \mathrm{~g}$ of $\mathrm{H}_{2} \mathrm{O}$ ice with $4.4 \% \mathrm{CO}_{2}$ (Ibadinov and Aliev 1987) (or $670 \mathrm{cal} \mathrm{g}^{-1}$ for the pure $\mathrm{H}_{2} \mathrm{O}$ ice). At experimental conditions equivalent to the conditions at 0.5 to $1.6 \mathrm{AU}$ (if the albedo is 0.7 ), such ice has a temperature of 216 to $180 \mathrm{~K}$, respectively. It is known that the pressure of saturated vapor at the surface of such a system is equal to the sum of the partial pressures of the components (Dalton's law). The partial pressure of the saturated impurity vapor is proportional to the impurity's concentration (Henry's law). At an ice temperature of $200 \mathrm{~K}$, the pressure of the saturated $\mathrm{CO}_{2}$ vapor is $1.3 \times 10^{5} \mathrm{~Pa}$, which is approximately $10^{6}$ times the vapor pressure of $\mathrm{H}_{2} \mathrm{O}$ ice at this temperature. The total pressure is $4 \times 10^{3} \mathrm{~Pa}$ when the $\mathrm{CO}_{2}$ concentration in the $\mathrm{H}_{2} \mathrm{O}$ ice composition is $3 \%$ at the above temperature. The sublimation of the volatile impurity increases with the ice temperature in proportion to the impurity's concentration (Dobrovolsky et al. 1986). The saturation pressure is close to $10^{4} \mathrm{~Pa}$ at the temperature of $230 \mathrm{~K}$. Due to the mineral crust's low permeability, the actual pressure is close to that of saturation and can reach $10^{3}$ to $10^{4} \mathrm{~Pa}$. This high pressure can result in the destruction of the crusts, which have strength properties analogous to those of the mineral crusts shown in Table 1.

A nucleus model of Comet Halley composed of $\mathrm{H}_{2} \mathrm{O}$ ice, graphite particles, and a few percent of volatile $\mathrm{CO}_{2}$-type impurities displays quasi-continuous destruction of the mineral crust of the nucleus surface, at least for conditions corresponding to $\mathrm{R}<1.5 \mathrm{AU}$. Another consequence is to the gas and dust production of the nucleus. The surface temperature of such a nucleus is expected to be as high as that of Comet Halley, and the surface albedo is several percent. Inhomogeneities of the $\mathrm{CO}_{2}$ concentration in the nucleus might be responsible for the occurrence of gas and dust jets from the comet. This model does not exclude a structured nucleus surface in the form of mineral-crust islands on an otherwise exposed icy surface.

\section{References}

Combes, M., et al. (1986). "Infrared sounding of comet Halley from VEGA I," Nature, $321,266-268$.

Dobrovolsky, O.V., and Ibadinov, K.I. (1971). "Destruction of dust matrix on comet nucleus surface," Dokladi Akademii Nauk Tadjik SSR, 14, 16-19.

Dobrovolsky, O.V., and Kajmakov, E.A. (1977). "Surface phenomena in simulated cometary nuclei," in A.H. Delsemme (ed.), Comets, Asteroids, Meteorites, The University of Toledo, Toledo, Ohio, 37-46.

Dobrovolsky, O.V., et al. (1984). "Secular brightness decrease and nuclei structure of periodical comets," Dokladi Akademii Nauk Tadjik SSR, 27, 198-200.

Dobrovolsky, O.V., et al. (1986). "Thermal regime and surface of periodic comet nuclei," in B. Battrick, E.J. Rolfe, and R. Reinhard (eds.), Exploration of Halley's Comet, Proceedings of the International Symposium held in Heidelberg, Germany, 27-31 October 1986, ESA SP-250, Vol. II, Noordwijk, The Netherlands, 389-394.

Emerich, C., et al. (1986). "Temperature and size of the nucleus of Halley's comet deduced from I.K.S. infrared VEGA I measurements," in B. Battrick, E.J. Rolfe, and R. Reinhard (eds.), Exploration of Halley's Comet, Proceedings of the International Symposium held in Heidelberg, Germany, 27-31 October 1986, ESA SP-250, Vol. II, Noordwijk, The Netherlands, 381-384. 
Fanale, F.P., and Salvail, J.R. (1984). "An idealized short-period comet model: Surface insolation, $\mathrm{H}_{2} \mathrm{O}$ flux, dust flux, and mantle evolution," Icarus, 60, 476-511.

Grün, E., et al. (1987). "Simulation of cometary nuclei," in E.J. Rolfe and B. Battrick (eds.), Diversity and Similarity of Comets, Proceedings of an International Symposium held in Brussels, Belgium, 6-9 April 1987, ESA SP-278, Noordwijk, The Netherlands, 501-508.

Ibadinov, K.I. (1982). "The durability of dust formed under the dusty ice sublimation," Komety i Meteory, 34, 19-23.

Ibadinov, K.I. (1989). "Laboratory investigations of the sublimation of comet nucleus models," Adv. Space Res., 9 (3), 97-112.

Ibadinov, K.I., and Aliev, S. (1984). "Laboratory investigation of the comet $\mathrm{H}_{2} \mathrm{O}, \mathrm{CO}_{2}$ and $\mathrm{NH}_{3}$ ice conglomerates," Komety i Meteory, 36, 35-37.

Ibadinov, K.I., and Aliev, S. (1987). "Sublimation characteristics of $\mathrm{H}_{2} \mathrm{O}$ comet nucleus with $\mathrm{CO}_{2}$ impurities," in E.J. Rolfe and B. Battrick (eds.), Diversity and Similarity of Comets, Proceedings of an International Symposium held in Brussels, Belgium, 6-9 April 1987, ESA SP-278, Noordwijk, The Netherlands, 717-719.

Ibadinov, K.I., and Kajmakov, E.A. (1970). "Formation and destruction of dust matrices during sublimation of dusty ice," Komety i Meteory, 19, 20-24.

Ibadinov, K.I., and Rahmonov, A.A. (1988). "Laboratory simulation layer on comet Halley nucleus surface," Kometny Circ., 395, 4.

Ibadinov, K.I., et al. (1985). "The formation rate and physical+mechanical characteristics of organic matrixes on the surface comet nuclei models," Dokladi Akademii Nauk Tadjik SSR, 28, 21-24.

Ibadinov, K.I., et al. (1987a). "Physical-mechanical properties of matrixes on the comet nuclei surface model," in E.J. Rolfe and B. Battrick (eds.), Diversity and Similarity of Comets, Proceedings of an International Symposium held in Brussels, Belgium, 6-9 April 1987, ESA SP-278, Noordwijk, The Netherlands, 713-716.

Ibadinov, K.I., et al. (1987b). "Laboratory investigation of thermal conductivity of dust models on the ice comet nuclei surfaces," in Z. Ceplecha and P. Pecina (eds.), Interplanetary Matter, Proceedings of the 10th European Regional Astronomy Meeting of the IAU, 24-29 August 1987, Praha, Czechoslovakia, 2, 55-57.

Kajmakov, E.A., and Ibadinov, K.I. (1971). "Influence of light on dusty ices," Komety i Meteory, 20, 9-13.

Klinger, J., et al. (1989). "How far do results of recent simulation experiments fit current models of cometary nuclei," in Proceedings of the 19th Lunar and Planetary Science Conference, Lunar and Planetary Institute, Houston, 493-497.

Kochan, H., et al. (1989). "Laboratory simulation of a cometary nucleus: Experimental setup and first results," in Proceedings of the 19th Lunar and Planetary Science Conference, Lunar and Planetary Institute, Houston, 487-492.

Lizunkova, I.S., et al. (1977). "Simulation of cometary dust particles," Sov, Astron. J., Letter 3, 518-521.

Markovich, M.Z. (1958). "Thermal conductivity of cometary nucleus surface layer," Bulleten Instituta Astrofiziki Akademii Nauk Tadjik SSR, 3-14.

Markovich, M.Z. (1961). "Nuclei temperature of comets with great aphelion distances," Bulleten Komissii po Kometam i Meteoram, 6, 25-31.

Markovich, M.Z. (1986). "On the theory of the "spotty' model of cometary nucleus," Kinematika i Fizika Nebesnykh Tel, 2, 70-76. 
Matveev, N.N., and Kajmakov, E.A. (1980). "Experimental research of the probable parent $\mathrm{Na}$ - and Li-containing molecules in comet," Komety i Meteory, 28, 17-25.

Mendis, D.A., and Brin, G.O. (1977). "Monochromatic brightness variations of comets. II. Core-mantle model," Moon, 17, 359-372.

Reinhard, R. (1986). "The Giotto encounter with comet Halley," Nature, 321 (6067), 313-318.

Riives, V.G. (1966). "Intensity of gas production in comets," Komety i Meteory, 13, 3-8.

Sagdeev, R.Z., et al. (1986). "VEGA spacecraft encounters with comet Halley," Nature, 321 (6067), 259-262.

Sekanina, Z., and Larson, S.M. (1986). "Coma morphology and dust emission pattern of Periodic Comet Halley. N. Spin vector refinement and map of discrete dust sources for 1910," Astron. J., 92, 462-482.

Shul'man, L.M. (1972). Dinamika kometnyh atmospher. Nejtralnyj gas, Naukova Dumka, Kiev.

Shul'man, L.M. (1987). Jadra komet, Nauka, Moscow.

Whipple, F.L. (1950). “A comet model. I. The acceleration of comet Encke," Astrophys. J., 111, 375-394.

Whipple, F.L. (1951). "A comet model. II. Physical relations for comets and meteors," Astrophys. J., 113, 464-474.

Yeomans, D.K. (1986). "The comet Halley ephemeris development effort," in R. Reinhard and B. Battrick (eds.), Space Missions to Halley's Comet, ESA SP-1066, Noordwijk, The Netherlands, 179-198. 